REPRODUCTION

\title{
A dualist analysis of abortion: personhood and the concept of self qua experiential subject
}

\author{
K E Himma
}

\section{Correspondence to: Kenneth Einar Himma, Department of Philosophy, University of Washington Box 353350, Seattle, WA 98195, USA: \\ KHimma@cs.com}

Received 18 June 2002 In revised form

10 December 2002

Accepted for publication

13 June 2003
J Med Ethics 2005;31:48-55. doi: 10.1136/jme.2002.000828

There is no issue more central to the abortion debate than the controversial issue of whether the fetus is a moral person. Abortion-rights opponents almost universally claim that abortion is murder and should be legally prohibited because the fetus is a moral person at the moment of conception. Abortion-rights proponents almost universally deny the crucial assumption that the fetus is a person; on their view, whatever moral disvalue abortion involves does not rise to the level of murder and hence does not rise to the level of something that should be legally prohibited.

In this essay, I argue that, under dualist assumptions about the nature of mind, the fetus is not a person until brain activity has begun. ${ }^{i}$ First, I argue it is a necessary condition for a thing to be a moral person that it is (or has) a self. Second, I argue it is a necessary condition for a fetus to be (or have) a self, under dualist assumptions, that there has been some electrical activity in the brain. I conclude that a dualist can take the position that abortion ought to be legally permitted at least until the beginning of brain activity in the fetus.

\section{THE CONCEPT OF THE SELF QUA SUBJECT}

In getting a sense for what, for the purposes of my argument, the concept of the self qua subject describes, it is helpful to reflect on conscious experience. When I am having a conscious experience of some kind, say a visual perception of a tree, I can distinguish, analytically at least, two different elements of that experience. The first is, of course, the visual image of a tree as it appears, so to speak, in or to my mind's eye. This image consists of a number of felt qualities that constitute the perceptual content of the experience. These qualities include shapes and colours that are arranged in particular patterns, such as, for example, those that we associate with the branches of a tree.

The second is an awareness of something I experience as an inner observer, an "inner I", as Todd E Feinberg puts it, ${ }^{1}$ to whom the image appears. ${ }^{\text {ii }}$ In my conscious experience of the tree, I am there as the observer or subject of that perceptual content. The perceptual content of the tree is present in my experience, but I —or something I identify as the referent of "I"-am also present in the experience. My conscious experience of the tree includes not only the perceptual content of the tree, but also its occurrence to me qua subject of that experience. My being there qua subject or inner observer is also an important part of what I experience when I look at a tree.

Both of these elements must be present in any conscious experience. The content of the perception of the tree is not, and could not be, simply a free-floating image in my mind without being noticed by this inner observer. If perceptual content is not noticed by something (or someone), then it is not conscious. ${ }^{\text {iii }}$ It is part of the very notion of a conscious experience that it happens to something (or someone) that functions as a mental subject.

The popular analogy of a theatre naturally suggests itself. On this conception, conscious experience is analogous to someone who watches a movie in a theatre. My sense organs are assimilated to the projector, which displays the visual input in a way that can be consciously observed. The content of my perceptual images is analogous to the images on the movie screen; both have been causally translated into an experiential medium. My inner observer, the subject of my perception of a tree, is analogous to the moviegoer who is experiencing the images on the screen. It is this inner observer or experiential subject that I will refer to as my "self qua subject". iv

The mental boundaries of the self qua subject of conscious experience, as I have described the notion, are considerably narrower than the boundaries of other loosely related concepts that the term "self" has been used to pick out." While some theorists have used the term "self" to pick out a collection of psychological characteristics that form the foundation for an individual's conception of who she is, the

Abbreviations: EEG, electroencephalogram

i I make no attempt to determine what conditions are sufficient for moral personhood; for this reason, the relevant claim about personhood is purely negative.

ii Feinberg describes the "inner $\mathrm{I}^{\prime}$ as the "subjective sense that we possess a single and unified point of view" and "the subject of experience" ${ }^{\prime \prime}$.

iii For example, I frequently find myself lost in thought while walking down the street. Usually, I "wake" with a start after a block or two wondering how in the world I managed to negotiate my way safely. On these occasions, what I experience as my inner observer is so preoccupied with some thought that it fails to notice visual images that it would otherwise notice. ${ }^{2}$

iv Though physicalist philosophers of mind tend immediately to dismiss intuitive talk of theatres and inner observers as naïve and unhelpful, it is a useful device for picking out the relevant mental phenomenon. As empirical researchers Josef Parvizi and Antonio Damasio, for example, describe the problem of the self: "The problem of how the movie in the brain is generated and the problem of how the brain also generates the sense that there is an owner and observer for that movie are so interrelated that the latter problem is nested within the former".

${ }^{\vee}$ As Eric T Olson points out, people use "self" to refer to very different things. ${ }^{3}$ 
use of "self" to pick out only the experiential subject-that is, the inner observer-excludes these characteristics. Those psychological characteristics that inform a person's self conception do not figure into the existence of the self qua subject of conscious experience; indeed, since those characteristics are largely formed, as a developmental matter, in response to conscious experience, the existence of those psychological characteristics presupposes the prior existence of the self qua experiential subject. The behaviours undertaken by the self qua subject will presumably be conditioned in part by those characteristics, but those characteristics are analytically distinct from the inner observer that is the referent of the term "self," as it is defined here.

Accordingly, the application of the concept self qua subject, unlike some of these other notions, is not limited to human beings. Since having a self conception that includes reference to psychological or personality characteristics presupposes the capacity for rationality (only a rational being can have a conception in the relevant sense), only human beings can have such self conceptions. While, however, it is thus true that human beings are the only beings on this planet that can have "selves" in this expanded sense, other animals have selves qua subjects. Because every conscious experience occurs in (or happens to) an experiential subject, every conscious being has a self in the sense of being an experiential subject (or having an inner observer). Thus, assuming animals such as cats, dogs, and cows are conscious, such animals have selves qua subjects.

It is worth noting that the concept of self qua subject is commonly used in a variety of intuitive settings. It is, for example, this very notion of self that is presupposed in religious thoughts such as: "I would like to be reincarnated as a dog", as well as more mundane thoughts such as: "I could have been born in Bill Gates's body". To the extent that such thoughts express causally or logically possible states of affairs, the thought must be that the inner observer that I identify as my self could be the subject of experiences that arise out of some other living physical body than my own; for it is clear in such cases (especially in the case of a dog) that one's psychology would likely be radically different from what it actually is. Indeed, it is the concept of self that is involved in the classical theistic hope that one's self can survive the physical death of one's body. ${ }^{\mathrm{vi}}$

\section{PERSONHOOD AND THE CONCEPT OF THE SELF}

It is usually thought that the issue of whether abortion ought to be legally permitted turns on the moral standing of the fetus. If, according to this familiar argument, the fetus is a moral person, then it has a right to life that, at the very least, defeats the mother's less important right to control her own body. If, on the other hand, the fetus is not a moral person, then the fetus simply does not have sufficient moral standing (even if it has some) to defeat a right of any kind; thus, a fortiori, it does not have sufficient moral standing to defeat the mother's right to control her own body. Accordingly, much energy has been focused on trying to articulate the criteria of personhood.

There are a couple of observations worth making at this point about the relationship between having moral standing

\footnotetext{
vi As I have described it, the concept of the self qua subject is comparatively narrow in a second important sense: the content of the concept does not contain any assumptions about the substantive character of the self. Though I wish to articulate a dualist theory of selfhood in this essay, the term "self", as I have defined it here, does not presuppose that the self qua subject is a substantial entity of any kind. Indeed, it does not even assume that the self is unified over time-that is, it does not assume that, for any distinct moments $t_{0}$ and $t_{l}$, my self at $t_{0}$ is the same as my self at $t_{1}$.
}

and having a self qua subject. One might reasonably think that an entity lacking a self can none the less be deserving of moral consideration in the deliberations of a moral agent. The idea, for example, that plants might have some limited moral standing strikes me as presumptively plausible despite the obvious fact that, lacking any capacity for mentality, plants do not instantiate anything that remotely resembles a self in the relevant respect. That some entity is biologically alive seems to be a morally relevant fact about it. ${ }^{45}$ Thus, it is reasonable to think that selfhood is not a necessary condition for moral standing in itself.

In contrast, what the relationship between selfhood and personhood - which is a particular level of moral standingturns out to be depends on what is meant by personhood. As is well known, the notion of personhood is ambiguous between the notion of genetic personhood and the notion of moral personhood. ${ }^{6}$ The notion of genetic personhood is usually defined in the following way: something is a genetic person if and only if it is a living being with human DNA. If what is meant by "personhood" is "genetic personhood", it should be clear that having a self is neither sufficient nor necessary for genetic personhood. It is not sufficient in so far as non-human animals, as seems reasonable, have selves in the relevant respect-which they must if they are conscious. It is not necessary in so far as an anencephalic living human infant lacks a self.

As it turns out, the notion of moral personhood is itself somewhat ambiguous. As Mary Anne Warren defines it, moral personhood is defined in terms of being a fully-fledged member of the moral community with a complete set of equal moral rights. But moral personhood has also been defined in terms that are largely psychological, the notion of personhood being associated with psychological characteristics such as personality - that is, the developed capacity or potential to interact in certain ways with other beings. The idea is that having the relevant set of capacities is what is meant by the relevant notion of personhood, but this notion entails being a member of the moral community.

Either way, it is reasonable to think that having a self is a necessary condition for being a moral person. Many theorists, for example, reject the idea that objects such as plants or artworks can have rights because they are not the kind of things that can plausibly be characterised as being able to hold or assert rights; to be a rights-holder, on this view, is to be able to assert oneself as a rights-holder and non-conscious entities are incapable of this. Since having a self is a necessary constituent of being conscious, it follows, if these theorists are correct, that a thing cannot be a rights-holder unless it has a self (though having a self might not be sufficient).

Even if such theorists are wrong, however, the suggestion that something could be a full-blown member of the moral community with a complete set of equal rights without having a self seems pretty clearly false as a matter of substantive moral theory. Although many people are prepared to accept the claim that non-human animals have rights in virtue of having the potential to suffer, one could, I suppose, take the even stronger position that there is no morally significant difference between human beings and non-human animals; thus, on this line of reasoning, nonhuman animals would have a full set of equal rights and thus be considered moral persons. But I know of no substantive or applied theorist who takes the position that non-conscious living entities such as plants have equal moral standing with human beings. What explains this difference, of course, is that animals have, whereas plants could not have, selves that function as experiential subjects. These intuitions suggest that having a self—or, at the very least, potentially having a 
self-is a necessary condition for being a full-fledged member of the moral community. ${ }^{\text {vii }}$

Likewise, it seems clear that a thing cannot instantiate personality unless it has a self (though, again, having a self may not be sufficient). The characteristics that confer personality are simply not properties that can be instantiated by something without a self. An ordinary robot, for example, can be programmed to simulate a sympathetic personality characteristic, but it cannot actually be sympathetic. (I say "ordinary robot" here because I do not want to assume that it will never be possible to build a conscious robot.) Sympathy is a feeling that expresses itself in behaviour-and not just a behaviour. To experience sympathy (as opposed to merely simulating sympathy), a thing must be capable of feeling, which, of course, presupposes the existence of a self qua subject. For this reason, an ordinary robot that is programmed to interact in certain ways with human beings is not plausibly characterised as personal because it does not have a self that can genuinely interact with other personal beings.

In thinking about abortion, it is important to realise that abortion-rights opponents and proponents generally agree on the general judgment that abortion is morally undesirable. What they disagree on is how undesirable it is: abortionrights opponents believe that abortion is murder because the fetus is a person with a right to life; thus, abortion should be legally prohibited. In contrast, abortion-rights proponents believe that, because the fetus is not a person, the moral undesirability of abortion does not rise to the level of murder; since the mother's reproductive rights outweigh any moral standing a fetus might have, abortion ought to be legally permitted. ${ }^{\text {viii }}$

This means that we can make some significant progress with respect to the issue of whether and when abortion ought to be legally permitted if we can determine when selfhood begins. Most abortion-rights opponents take the position that abortion should be prohibited because it always involves the intentional killing of a moral person and is hence murder; on this view, the fetus is a person from the moment of conception. If, however, selfhood is a necessary condition for personhood and the fetus does not acquire a self until some point $S$ beyond conception, then it follows, at the very least, that a very different kind of argument would have to be given to support a legal prohibition against abortion during the period that begins at conception and ends at $S .{ }^{\text {ix }}$

In the next two sections, I will attempt to determine what can be said about the necessary conditions for selfhood under dualist assumptions. For various reasons, I will not attempt to resolve the prohibitively difficult problem of identifying

vii One might take the position that human beings are moral persons even before developing a self in virtue of having an essential animal character-that is, of the species Homo sapiens. Even so, it is important to realise that such an animal character includes reference to the property of being sentient, which presupposes the existence of a self qua subject; as we saw above, non-human animals also have such selves. One way or another, it seems reasonable to conclude that the property of being a self qua subject plays some essential role in determining moral personhood. I am indebted to an anonymous referee for this point.

viii Of course, Judith Jarvis Thomson argues that even if we assume that the fetus is a moral person, it does not follow that it has a right to life that would entitle it to use the mother's body.?

ix This tells us nothing about whether abortion is plausibly characterised as "murder" after the instantiation of a self because selfhood is not obviously a sufficient condition for personhood-and the concept of "murder" applies only to the killings of moral persons. It seems clear, for example, that conscious non-human animals have selves but are not moral persons; for this reason, even animal rights proponents who believe that it is wrong to intentionally kill animals to eat them are hesitant to characterise such killings as "murder". sufficient conditions for the occurrence or instantiation of selfhood. Instead, I will argue that, under dualist assumptions, the instantiation of brain activity is a necessary condition for selfhood in the fetus. Thus, the fetus simply cannot be or instantiate a self until brain activity begins to occur.

\section{THE TENETS OF SUBSTANCE DUALISM}

The version of substance dualism that I want to consider here consists of four theses. First, according to the ontological thesis, there are two kinds of entity in this world capable of instantiating causally efficacious properties and capable, at least in principle, of existing independently of each other: material substances (bodies) and immaterial substances (minds or souls). Second, according to the composition thesis, a human being is a composite of a material substance (that is, a body that has certain biological properties) and an immaterial substance (that is, a mind or soul). Third, according to the self thesis, the soul is identical with the self qua subject: the soul constitutes the inner observer that is experienced by the person as self. Fourth, according to the interaction thesis, material bodies and immaterial minds are capable of causally interacting in both directions. In particular, immaterial minds are capable of causing effects in material bodies, and material bodies are capable of causing effects in immaterial minds.

It is worth noting that, although one can be a dualist without subscribing to the interaction thesis, ${ }^{\mathrm{x}}$ most contemporary substance dualists are classical theists who owe their ontological views, at least in part, to religious doctrines that also commit them to the interaction thesis. Classical theists generally conceive of God as an immaterial being who created the physical universe from nothing. These doctrines immediately entail both the ontological thesis and the interaction thesis. ${ }^{x i}$ Because God is an immaterial being who created the physical universe, God is a substance capable of existing independently from any physical object; thus, if classical theism is true, then the ontological thesis must also be true. In so far as God brings the physical universe into existence and sustains it, God is capable of causing things to happen in material entities; in so far as God can have something resembling perceptual experience of the material world, the material world is capable of causing effects in God. At the very least, then, the theist is committed to the interaction thesis as it pertains to God.

Strictly speaking, a classical theist could leave it at that, but this view is hard to reconcile with the scriptures of the various theistic traditions. On traditional translations, these scriptures conceive of human beings as being composites of body and soul. The Old Testament, scripture to both Christianity and Judaism, frequently speaks of human beings as having souls. "O keep my soul and deliver me" $\mathrm{e}^{\prime 9}$ and "Gather not my soul with sinners"10 are just a couple of examples from the Psalms. Similarly, the Book of the Cow in the Koran assumes that human beings either are or have

x Leibniz, for example, went so far as to claim that minds and bodies do not causally interact at all. The appearance of correlation between mental and physical states arises because of God's intervention; God simply synchronised the relevant mental and physical states in a "preestablished harmony".

xi Many theists have been led to reject substance dualism as a theory of mind by the mind/body problem, ${ }^{8}$ but this does not succeed in avoiding the problem because exactly the same problem arises with respect to the issue of how an immaterial God can causally interact with a physical world. The problem is that the immateriality of God is explained in terms of precisely the same properties that characterise the immateriality of souls. If it is the fact that an immaterial soul lacks extension and solidity that entails that it cannot causally interact with material bodies, then the fact that an immaterial God lacks those properties entails that God cannot causally interact with material bodies. 
souls: "Evil is that for which they have sold their souls-that they should deny what Allah has revealed, out of envy that Allah should send down of His grace on whomsoever of His servants He pleases; so they have made themselves deserving of wrath upon wrath, and there is a disgraceful punishment for the unbelievers".."

Further, on such translations, the scriptures traditionally conceive of the soul as the seat of moral agency. Leviticus 5:1, for example, states that "if a soul sin, and hear the voice of swearing, and [is] a witness, whether he hath seen or known [of it]; if he do not utter [it], then he shall bear his iniquity". ${ }^{12}$ Similarly, verses 2.281 and 2.286 of the Book of the Cow state, respectively, that "every soul shall be paid back in full what it has earned" and "Allah does not impose upon any soul a duty but to the extent of its ability". ${ }^{13}{ }^{14}$ Such passages, and there are many in both scriptures, seem to commit the theistic dualist to the claim that human souls interact with bodies. In any event, what follows applies only to versions of substance dualism that accept all four theses.

\section{MORAL PERSONHOOD AND ENSOULMENT}

These four tenets of dualism imply, at the very least, that moral personhood does not begin until the fetus is, so to speak, inhabited by a soul. If persons are conceived as being essentially composites (or unities) of bodies and souls, then a genetically human fetus does not become a person in the relevant moral sense of having a full-blown set of rights until there is a soul that is associated in the right kind of way with the body of the fetus. Of course, in this case, one might reasonably think that a fetus lacking a soul deserves some respect in virtue of being a human body that is an essential ingredient to personhood, but such respect will arguably fall short of that owed to a person. The concept of personhood is supposed to mark the distinction between merely being genetically human and being a bearer of rights; to the extent that a fetus lacking a soul is not a person, it will not bear rights. Even if such a being has moral standing, it will necessarily be less than that of a person with a full set of the basic moral rights.

As a historical matter, classical theists have taken a stronger view about the connection between ensoulment and personhood: ensoulment is both necessary and sufficient for moral personhood. In this connection, it is important to realise that the concept of ensoulment picks out the moment at which the soul is first united to the body and thus presupposes the existence of a body. ${ }^{\text {xii }}$ Thus, in so far as ensoulment is necessary and sufficient for personhood, the fetus becomes a person at that moment when it becomes a composite of body and soul; prior to this moment, the fetus is simply a material object and hence not a person-though, again, it surely deserves some respect.

There has been a great deal of disagreement among classical theists about when ensoulment occurs. Some Jewish theologians, for example, have taken the position that ensoulment takes place upon the birth of the child; thus, on this view, the fetus becomes a person at birth. Many prominent Christian theologians have also subscribed to a theory of delayed ensoulment (or homanisation). Augustine, for example, took the view that early abortion does not rise to the level of murder because "there cannot be a living soul in a body that lacks sensation due to its not yet being fully formed". xiii Influenced by Aristotle, Augustine took the curious position that ensoulment takes place in the male

xii Nevertheless, it is worth noting that, for many traditions, a disembodied soul is not a person. According to the Catholic Encyclopedia, for example: "The human soul belongs to the nature as a part of it, and is therefore not a person, even when existing separately". ${ }^{\prime \prime}$ fetus at 40 days and in the female fetus at 80 days. ${ }^{17 x i v}$ of course, theistic proponents of delayed ensoulment have generally agreed that abortion is immoral, not because it is murder, but because it makes possible sexual activity without procreation.

In recent years, classical theists have tended to reject theories of delayed personhood. Indeed, the most predominant view among Christian theologians seems now to be that ensoulment occurs at the moment of conception and hence that the fetus becomes a moral person at that time. At the very least, this highly controversial view is the most common view among lay theists in the United States who describe themselves as Christians. According to this familiar view, then, abortion always results in the murder of an innocent moral person and hence should be legally prohibited from the moment of conception.

Dualist proponents of the view that the fetus is a person from the moment of conception have, however, never given much argument for the underlying claim that ensoulment occurs at the moment of conception. Although proponents frequently argue that the fetus is an independent human life from the moment of conception, being an independent human life simply requires the instantiation of the properties of being alive, having human DNA, and being independent in the relevant sense; it does not obviously require the instantiation of a soul. For this reason, the dualist view that the fetus is a person from the moment of conception lacks support that is absolutely critical given the underlying view that personhood begins at ensoulment. ${ }^{\mathrm{xv}}$

In the next section, I will attempt to determine what can be said about when ensoulment occurs (and hence personhood begins) under dualist assumptions.

\section{THE CAUSAL NATURE OF THE CONCEPT OF ENSOULMENT}

Although the dualist notion of ensoulment presents a number of difficult issues, this much is certainly correct: the very notion of ensoulment is, at least in part, an inherently causal concept. Given that the soul is the seat of both the self and agency, it can be joined to a body only to the

xiii Augustine's position is presumably an attempt to give philosophical expression to Exodus 21:22-24, which treated the crime of causing a miscarriage as a comparatively small offence; the penalty was to pay whatever fine the husband deemed appropriate. (Exodus 21:12 requires the death penalty for murder. $)^{16}$

xiv Aristotle believed that abortion that is "procured before sense and life have begun" is morally permissible. ${ }^{17}$

$x v$ Jason Eberl argues that a zygote does not constitute a unique human life until it is implanted in the uterine wall because, prior to this point, the zygote is capable of splitting into multiple human beings: "[P]rior to implantation, each cell or group of cells has the power to separate from the rest of the zygote, divide by cellular mitosis, and develop into a multicellular organism. It is due to this totipotency of preimplantation cells that identical twins, triplets, etc are able to occur. One or more cells break away from the cluster, divide (mitosis), and develop into a second (or third, fourth, etc) organism. Because each cell or group of cells is its own unique individual biological entity and has the capacity to separate and develop into a distinct multicellular biological organism, it cannot be said that there is already an individual human organism at this point. In potentiality, there are, practically speaking, one or a few individual human organisms present. ${ }^{\prime \prime 18}$ Eberl's analysis, however, is problematic because twinning remains at least a theoretical possibility throughout the life of an adult human being. If, as some theorists believe, splitting a single human brain into two halves could result in two distinct subjects of experience, then Eberl's reasoning falsely implies that, for example, I am not a unique person because twinning remains a causal possibility. I am indebted to an anonymous referee for this important point. For a comprehensive evaluation of so called divisibility or twinning arguments, see Christian Munthe's paper. ${ }^{19}$ 
extent that it is possible for it to exercise some sort of causal influence on the body. ${ }^{\mathrm{xvi}}$ As John Foster rightly observes:

[A]s the dualist conceives the relation between body and mind, the very notion of embodiment will turn out to be, in part, implicitly causal. An essential part of what makes it the case that a certain mind and a certain body belong to the same subject is that they are causally attached to each other in a special way-a way which equips the body to have direct causal interaction with the mind, and no other, and equips the mind to have direct causal interaction with this body, and no other. ${ }^{20}$ xvii

At least part of what constitutes a given body as ensouled, then, is that the relevant body and soul are capable of direct causal interaction. Thus, whatever the crucial tie between a soul and its body turns out to be, it will have to involve some sort of causal connection between the soul and the body. ${ }^{\text {xiii }}$

Moreover, the causal connection will have to involve the soul and the physical brain because the empirical evidence seems clearly to show that the movements of the body are the immediate causal results of certain kinds of brain states that correlate with mental states associated with volitions. As Richard Swinburne, one of the most prominent and controversial defenders of dualism, summarises the evidence:

The evidence of neurophysiology and psychology suggests most powerfully that the functioning of the soul depends on the operation of the brain... When direct evidence shows that he is conscious, the electrical rhythm of a man's brain, his

xvi The reader who disagrees should consider the following analysis conditional: if the assumption that ensoulment necessarily involves a causal connection between soul and body is true, then the analysis of this section is correct. Thus, someone who disagrees with this analysis could always view it as a reductio of the assumption that ensoulment is inherently causal.

xvii The same remarks, of course, apply to the notion of ensoulment since it is an extensionally equivalent notion: the locution "the body is ensouled" and the locution "the soul is embodied" pick out exactly the same states of affairs. ${ }^{20}$

xviii It follows that if souls are located in space and time (as is sometimes thought by philosophical lay persons), the mere co-occupation by a soul and body of successive positions in space is clearly not sufficient to give rise to the relevant relation between a soul and a material being; souls do not inhabit bodies the way people inhabit buildings - that is, by means of spatial occupation.

ixx Indeed, it is worth noting that Swinburne anticipates that this kind of analysis may have implications for abortion - though he does not resolve those issues: "So, given that the soul functions first about twenty weeks after conception, when does it come into existence? There exist normal bodily processes by which the fertilised egg develops into a fetus with a brain after twenty weeks which gives rise to a functioning soul. If the soul exists just because normal body processes will bring it one day to function, it surely therefore exists, once the egg is fertilised, at conception. On the other hand one might say that normal processes need to be fairly speedy ones if the soul is to exist during their operation; and so that the soul begins to exist, only shortly before it first begins to function" (Swinburne, $p$ 179). Swinburne remarks that "it seems an arbitrary matter when we say that the soul begins to exist" (Swinburne, p 179), but none the less endorses the second view as more natural. Accordingly, he would presumably take the position that abortion is not murder until "shortly before" the soul begins to function, which he takes to be 20 weeks. Swinburne's view of personhood is as follows: $X$ is a composite of body and soul if and only if $X^{\prime}$ s soul can be made to function by $X^{\prime}$ s body through some process that is "normal" in the sense that "it will yield its outcome with a high degree of predictability given normal nutrition, respiration, etc, without sophisticated medical intervention; and by a technique being 'available', that it is available to doctors during that period of history within a region of the size of the average county" (Swinburne, p 178). A fetus is a composite of body and soul and hence a moral person if and only if the relevant causal link exists between the functioning of its soul and the operation of its body. The reader sympathetic to Swinburne's view can take my analysis as an analysis of what "normal processes" require as a necessary condition.
EEG, is found to have a certain pattern. The EEG varies with the kind of consciousness - there is one kind of EEG rhythm for intense thought, another kind when a man is mentally inactive but awake, another kind when he is dreaming...; and there are different rhythms for sleep of different kinds, when the man has no recollection of dreaming...EEG rhythms are thus indirect evidence of consciousness. ${ }^{21}$

Although Swinburne concludes, somewhat cryptically, that while the soul can exist without the brain, it is clear that he accepts, as he must, that the locus of the causal connection between the soul and body is the brain: "the functioning of the soul depends on the correct functioning of the brain" (Swinburne, p 176). ${ }^{\text {ixx }}$

Of course, dualists are likely to identify the instantiation of mental states in the soul as the ultimate cause of any sort of behavioural movement. On this view, action can be modelled very roughly as follows: (1) a volition $V$ to do $A$ occurs in the soul; (2) $V$ causes a brain state $B$ that embodies that volition, and (3) $B$ causes the body to perform the movements associated with $A{ }^{\text {xx }}$

This, however, commits the substance dualist to the following proposition describing the connection between soul and body. Since the immediate cause of any bodily movement or behaviour is some sort of physical brain state, the mechanism that ties soul to body-whatever it turns out to be-cannot occur until it is possible for the soul to exercise causal influence over brain states.

This means, at the very least, that ensoulment cannot occur in the fetus until it has something that counts as a brain. If (1) ensoulment cannot occur until there is a direct causal connection between the soul and body, and (2) such a connection must occur between the brain and soul, then it follows that ensoulment cannot occur in the fetus until it has a brain. Of course, in this context, the application conditions for the locution "having a brain" will necessarily be somewhat vague, as there is probably no moment in fetal development that can plausibly be characterised as the moment at which the fetus goes from a being without a brain to a being with a brain. It will certainly be possible, however, on the strength of the empirical evidence, to confidently conclude that zygotes lack brains. Thus, if substance dualism is true, personhood cannot begin at either conception or implantation. ${ }^{\mathrm{xxi}}$

x Much more would obviously be needed to make out this rough model-including, of course, providing some sort of account of how such interaction is possible-but something like this, I think, fairly characterises the predominant dualist view of agency.

xxi Eberl argues that implantation is also sufficient for personhood on the ground that the fetus becomes capable at implantation of performing certain functions only the soul can perform: "At the formation of the primitive streak, there is a living biological organism, capable of nutrition and growth, developing the earliest biological tools necessary for sensation, imagination, and rational thought (being that all of these powers are tied to the brain and spinal cord that develop from the primitive streak)...The specific powers of sensation and intellection are not themselves actualised until the required organs begin to function. However, the soul is active by informing the body to develop the required organs. Therefore, I conclude that the human person is instantiated as an individual complete biological organism with the powers of life, sensation, and rational thought (that is, a being with both a body and a human intellective soul) at the moment the primitive streak begins to form, division of the organism (that is, twinning) is no longer possible, and cells that form the embryo proper are determined to that end and no other" (Eberl, pp 149-150). This analysis is problematic because the fetus does not have a developed individuated brain structure at this point (much less a functioning brain). Only several days after implantation do even the precursors of the various organs begin to emerge-for example, the notochord, ectoderm, and mesoderm (which will at some point become the nervous system, ribs, and muscles) are formed in the week or so after implantation occurs. Clearly, there are empirical and conceptual problems with attributing even "unactualised" powers of rational thought and sensation to the fetus at implantation. 
A more ambitious conclusion is, however, possible here. The soul cannot cause a brain state unless more than one brain state is possible-and this requires that the brain be capable of more than just the brain state that consists of no electrical activity, which I will call, for lack of a better term, the empty brain state. ${ }^{\text {xxii }}$ In addition, the brain must develop to a point where active brain states can occur. This implies, however, that personhood cannot occur on a dualist view until brain activity begins. Since, at the very least, the brain must have developed to a point where non-empty or active brain states occur and such states cannot, as a conceptual matter, occur in the absence of electrical activity (which, of course, is what makes them active brain states as opposed to the empty state), it follows that selfhood cannot begin until there is brain activity. Because the instantiation of selfhood is a necessary condition of moral personhood, it follows that, even if dualism is true, personhood cannot occur until brain activity begins.

\section{RELEVANT TYPES OF NECESSARY BRAIN ACTIVITY}

The claim that brain activity is necessary for moral personhood, though certainly a reasonable conclusion to draw from the preceding analysis, is somewhat unclear. The fetal brain develops very gradually over time from a comparatively simple structure consisting largely of no more than an inchoate brainstem to a more complex structure that comprises a number of functionally differentiated neurological components, including the critical cortex. The occurrence of different forms of brain activity begins, as one would expect, at different stages in fetal development; after all, cortical brain activity cannot begin until there is a differentiated cortical structure.

There are at least two stages that are potentially relevant with respect to the issue of when selfhood emerges: (1) the very first occurrence of brain activity in the fetus; and (2) the beginning of cortical activity. The very first electrical activity that is associated with the brain occurs in the brainstem of the fetus. Though there has been at least one report of brain activity occurring as early as seven weeks into pregnancy, ${ }^{22}$ researchers have determined that the first electroencephalogram (EEG) activity usually occurs in the brainstem at around 10 weeks of gestational age. ${ }^{23}$

Cortical activity begins much later. Empirical data indicate that conscious activity begins as a series of isolated discontinuous episodes at around 22 weeks of gestational development. ${ }^{24}$ As Burgess and Tawia describe this stage of development:

\section{Between 22 and 25 weeks of gestation the most distinctive feature of EEG activity is its discontinuous nature. At this stage of development the EEG is made up of bursts of activity of up to 20 seconds interspersed with periods of no activity for up to 8 minutes. At 24 weeks, periods of activity occupy an average of only $2 \%$ of the EEG recording time and the EEG consists of a variety of slow waves (Burgess, et al, p 20). ${ }^{24}$}

These periods of EEG inactivity, which indicate, among other things, the absence of conscious mental states, diminish as the fetus develops until around 29 to 35 weeks at which time EEG activity becomes more consistently continuous, comprising over $80 \%$ of recording time. Indeed, most researchers generally locate the beginning of consciousness at this point. Thus, although discontinuous cortical activity typically

xxii A state of the brain that is completely inactive is, after all, a state of the brain. commences in the fetus at around 20 weeks of gestational age, consistent cortical activity begins at approximately 29 to 35 weeks of gestational age.

At the very least, it is reasonable to conclude on the basis of the analysis of the previous sections that the fetus cannot be (or have) a self and hence cannot be a moral person prior to the beginning of electrical activity in the brainstem. Under dualist assumptions, the fetus cannot be a person until it is a causal composite of body and soul (which is traditionally conceived by substance dualists as the seat of self). There can, however, be no meaningful association between soul and body that does not establish a causal connection between self and brain. Since there can be no causal connection with the brain in the absence of active brain states and active brain states are not possible unless there is electrical activity in the brain, it follows that the fetus cannot be a person until electrical activity begins in the brainstem.

Thus, under dualist assumptions, there are no moral grounds for a legal prohibition of abortion prior to the beginning of fetal brain activity. This does not entail that abortions performed prior to fetal brainstem activity are morally permissible, but it does entail that whatever moral wrong occurs as a result of such abortions does not rise to the level of murder and hence does not rise to the level of something that ought to be legally prohibited by the state. Thus, it appears that we can conclude, at the very least, that abortions performed prior to the onset of brain activity (including use of the controversial "abortion pill") ought to be legally permitted.

The issue is whether we can draw a stronger conclusion on the basis of this sort of analysis-in particular, whether we can conclude that abortion ought to be legally permitted prior to the beginning of cortical brain activity. ${ }^{x i i i}$ Here it is important to note that cortical activity is intimately associated with the higher functions of consciousness, including sense perception, rational thought, emotion, intentionality, and action. Profound and irreversible trauma to the cortex usually renders the patient permanently comatose, resulting in the loss of all the functions usually associated with meaningful life, ${ }^{26}$ which include, according to Henry Beecher, "the individual's personality, his conscious life, his uniqueness, his capacity for remembering, judging, reasoning, acting, enjoying, worrying, and so on" ${ }^{27}$ Indeed, given this apparent centrality of cortical activity to consciousness, some have argued for a criterion of death that makes reference to only the functions of the higher brain; on this line of analysis, the current definition of death as involving cessation of all brain activity is too conservative. ${ }^{\text {xxiv }}$

Of course, it is widely acknowledged that the brainstem plays some kind of essential role in these higher functions of consciousness. For example, the brainstem is necessary for the normal functioning of the respiratory and cardiovascular systems, without which conscious life is not possible. Similarly, the brainstem serves as a conduit that transmits information between the spinal cord and the brain, making possible physical movement and hence action; severe damage to the spinal cord or brainstem usually results in partial or total paralysis. Accordingly, most researchers agree that the normal functioning of the brainstem is necessary for autonomous action.

The brainstem is also thought, however, to play some sort of essential role in the capacity for consciousness itself. The

xxiii Swinburne seems to take this view. ${ }^{21}$

xxiv See the paper by Robert Veatch in the Hastings Center Report. ${ }^{28}$ As the reader may notice when reading this paper, the issue of when personhood ends is not irrelevant with respect to the issue of when it begins; if one takes the view that personhood ends with the cessation of the higher functions of the brain, it would seem to follow that personhood begins with the beginning of those functions. 
brainstem is known, for example, to regulate cycles of wakefulness and sleep; because wakefulness is essential not only for the higher functions of conscious life, but also for the basic function of brute awareness that constitutes the state of being conscious, this function of the brainstem appears essential to consciousness itself. Indeed, severe damage to this area of the brainstem typically results in a permanently comatose state, suggesting that the brainstem plays an indispensable role in the production of consciousness.

Nevertheless, it is important to note that these roles are indirect in an important way. A beating heart, for example, plays an indispensable role in consciousness; a genetically human being cannot be conscious without a heart that functions well enough to keep him or her biologically alive. It is clear, however, that such a functioning heart does not, as a causal matter, give rise to consciousness and hence that the activity of the brainstem in regulating cardiovascular function does not play a direct role in any conscious experience. Similarly, the transmission of information from spinal cord to cortex is necessary for sense perception and conscious agency, but this function of the brainstem does not give rise to either aspect of conscious life. Finally, although the brainstem regulates cycles of wakefulness and sleep, the role that it plays here is sometimes metaphorically described as playing the role of the light switch and not the role of the light itself; just as an operating light switch is indispensable for getting the light on but not what causally gives rise to the light, the regulation of alertness and stupor is indispensable to, as it were, switching consciousness on, but not what causally gives rise to consciousness.

Indeed, even those empirical researchers who are most optimistic about a link between brainstem and self limit their optimism to only an indirect link of the kind described above. For example, consider the view of Parvizi and Damasio, who suggest that the brainstem plays a role in the constitution of a "proto-self":

The organism...is represented in the brain by a coherent collection of neural patterns which map, moment by moment, the state of the organism in its many dimensions. This ceaselessly maintained first-order collection of neural patterns is described in the proposal as the "proto-self." The proto-self occurs not in one brain region but in many, at a multiplicity of levels, from the brainstem and hypothalamus to the cerebral cortex, in structures that are interconnected by neural pathways. These structures are intimately involved in the processes of regulating and representing the state of the organism, two closely tied operations. In short, the proto-self is a coherent collection of neural patterns which map, moment by moment, the state of the physical structure of the organism in its many dimensions (Parviizi, et al, ${ }^{2}$ p 138, emphasis in original).

Though Parvizi and Damasio believe the role the brainstem plays in the construction of the proto-self is direct (in the causal sense of giving rise to the proto-self), they are clear in rejecting the claim that the proto-self constitutes the

${ }^{x x y}$ Again, it is important to emphasise that this does not imply that abortion is morally permissible prior to this point; rather, it implies only that the impermissibility does not rise to the level of that associated with murder.

xxvi Because there is at least one study that reports such activity prior to 7 weeks of gestational age, ${ }^{22}$ it should be noted that only $13.8 \%$ of abortions are performed prior to the 7th week of pregnancy. In any event, occurrence of brainstem activity prior to 10 weeks is the exception and not the rule. experiential subject or inner observer that is experienced as self:

The proto-self is not...the sense of self on which our current knowing is centred, that is, the core self (the protagonist of core consciousness), and the autobiographical self (the extended form which includes one's identity...) [but rather] is the pre-conscious biological precedent of both core and biological self' (Parvizi, et al, ${ }^{2}$ p 138, emphasis added).

The relevant mappings are a necessary precondition, on this line of analysis, for the emergence of the self (in the sense that I have described), but the relevant mappings themselves do not give rise to that self.

Although it would hence not be entirely unreasonable, as an epistemic matter, to infer that the fetus cannot be a person prior to the beginning of higher brain activity, there is a moral reason for caution. After all, if the instantiation of a self in a human fetus is a sufficient condition for moral personhood, the moment at which the fetus instantiates a self marks the beginning of the period during which the moral impermissibility of abortion rises to the level of murder. ${ }^{\mathrm{xxv}}$

Accordingly, moral considerations may dictate acting on (as opposed to accepting) a more conservative conclusion about fetal personhood; for allowing abortion after 10 weeks, given the epistemic uncertainty associated with fetal personhood, runs a substantial risk of resulting in murder. Hence, even if there are reasonable epistemic grounds for believing that the selfhood/ensoulment cannot begin until the first episodes of cortical brain activity, there are strong moral grounds that preclude basing the law on such a belief.

Either conclusion, however, entails reasonably extensive abortion-rights. Because, according to Centers for Disease Control (CDC) figures, $91 \%$ of all abortions are performed within the first trimester, ${ }^{29}$ a law that permitted abortions up to the beginning of discontinuous cortical activity would have the effect of allowing abortions up to 20 weeks and hence permit all first trimester abortions and then some. Further, because, according to CDC figures, $74.5 \%$ of all abortions are performed within the first 10 weeks, a law that permitted abortions up to the beginning of brainstem activity would have the effect of allowing most abortions up to 10 weeks. ${ }^{29}$ xxvi In either case, a substantial number of abortions would be allowed under a law that permitted abortion until the beginning of the relevant form of brain activity.

\section{ACKNOWLEDGEMENTS}

Some of the analysis in this paper appears in a companion piece. Himmia KE. What philosophy of mind can tell us about the morality of abortion: personhood, materialism, and the existence of self. Int $J$ Appl Philos 2003;17:73-93. Reproduced here with the permission of the publisher. In this essay, I argue that under a physicalist (or materialist) theory of mind, it is a necessary condition of having a self (and hence of being a person) that electrical activity occurs in the brain.

I am grateful to Ashley Greenwell for her generous help with the empirical research. Her efforts should not be construed as an endorsement of the conclusions I have reached.

Please see page 56 for a reply to this paper.

\section{REFERENCES}

1 Feinberg TE. Altered egos: how the brain creates the self. Oxford: Oxford University Press, 2001:6, 5.

2 Parvizi J, Damasio A. Consciousness and the brainstem. Cognition 2001;79:135-60 at 137.

3 Olson ET. There is no problem of the self. In: Gallagher S, Shear J, eds. Models of the self. Thorverton: Imprint Academic, 1999.

4 Taylor P. The ethics of respect for nature. Environ Ethics 1981;3:197-218. 
5 Goodpaster KE. On being morally considerable. J Philos 1978:75:308-25.

6 Warren MA. On the moral and legal status of abortion. Monist 1973;57:43-61.

7 Jarvis Thomson J. A defense of abortion. Philos Public Aff 1971;1:47-66.

8 Murphy N. Reconciling theology and science. Kitchener, Ontario: Pandora Press, 1989.

9 Holy Bible. Psalms 25, 20.

10 Holy Bible. Psalms 26, 9.

11 Koran. Book of the Cow: 2.90 .

12 Holy Bible. Leviticus v, 5:1.

13 Koran. Book of the Cow: 2.281.

14 Koran. Book of the Cow: 2.286.

15 The Catholic Encyclopedia http://www.newadvent.org/cathen/11726a.htm (accessed 26 Sept 2004).

16 Holy Bible. Exodus 21, 22-4.

17 Aristotle. The politics [trans Sinclair TA]. London: Penguin, 1981:397.

18 Eberl JT. The beginning of personhood: a Thomistic biological analysis. Bioethics 2000;14:134-57 at 142.

19 Munthe C. Divisibility and the moral status of embryos. Bioethics $2001 ; 15: 382-97$
20 Foster J. The immaterial self: a defence of the Cartesian dualist conception of the mind. London: Routledge, 1991:165-6.

21 Swinburne R. The evolution of the soul [revised ed]. Oxford: Oxford University Press, 1997:174-5.

22 Borkowski WJ, Bernstine RL. Electroencephalography of the fetus. Neurology 1955;5:362-5.

23 Bergstrom RM, Bergstrom L. Prenatal development of stretch reflex functions and brainstem activity in the human. Ann Chir Gynaecol Fenn 1963;52(suppl): 1-21S.

24 Burgess JA Tawia SA. When did you first begin to feel it? Locating the beginning of consciousness. Bioethics 1996;10:1-26.

25 Concar D. Into the mind of the unborn. New Sci 1996;152:40-5.

26 Jennett B, Plum F. Persistent vegetative state after brain damage: a syndrome in search of a name. Lancet 1972;1:734-7.

27 Veatch RM. Death, dying, and the biological revolution. New Haven: Yale University Press, 1976:38.

28 Veatch RM. The impending collapse of the whole brain definition of death. Hastings Cent Rep 1993:23:18-24.

29 Anon. Morbidity and mortality weekly report. Centers for Disease Control 1994;43:50.

\section{$\mathrm{ECHO}$}

\section{Waiving consent in emergencies helps patients}

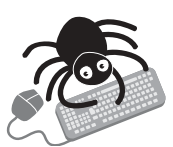

Please visit the Journal of Medical Ethics website [www. jmedethics. com] for a link to the full text of this article. aiving consent to receive research treatment in life or death situations may help $\checkmark$ patients in more ways than one, according to evidence from an international multicentre randomised controlled trial (RCT) of head injuries in unconscious patients.

It showed that waiving relatives' consent allows patients to be treated sooner with potentially more benefit. It may also increase patient enrolment into trials, enabling the formal process of identifying effective new treatments for life threatening injuries.

Mean time to randomisation (and treatment) in the trial was significantly longer in those hospitals where consent was required compared with those where it was not (4.4 (SE $0.21) \mathrm{h} v 3.2(\mathrm{SE} \mathrm{0.16)} \mathrm{h}$ ) and fewer patients were enrolled per month (1.5 (SE 0.24) $v 2.0$ (SE 0.29)).Though not proved, it seems reasonable that obtaining consent entailed some extra time. This was clinically important as treatment was needed within eight hours after the injury occurred and, ideally, as soon as possible to stand a chance of being effective.

The MRC CRASH trial is running in 160 hospitals in 40 countries with 4000 patients. Ethics committees in 78 hospitals have agreed to waive consent and the rest require relatives' consent.

In emergencies patients may be unable to give consent themselves, but RCTs are essential in such situations to identify future treatments to prevent death and disability. Many ethics committees allow patients to take part in these trials without consent-those that do not risk delaying potentially lifesaving treatment, especially for neurological injuries, when time is crucial.

A The CRASH Trial Management Group. Emergency Medicine Journal 2004;21:703. 